\title{
ОБ МЕТОДОЛОГИИ ОЦЕНКИ ЭКОНОМИЧЕСКИХ ЗАТРАТ ПО ОКАЗАНИЮ МЕДИЦИНСКОЙ ПОМОЩИ ПОЖИЛОМУ НАСЕЛЕНИЮ В РОССИЙСКОЙ ФЕДЕРАЦИИ
}

\author{
(c) 2020 Листопад Екатерина Евгеньевна \\ кандидат экономических наук, доцент департамента аудита и корпоративной отчетности \\ Финансовый университет при Правительстве РФ, Россия, Москва \\ E-mail:EEListopad@fa.ru \\ (C) 2020 Мустафаева Сима Раджеддиновна \\ аспирант Департамента бизнес-аналитики \\ Финансовый университет при Правительстве РФ, Россия, Москва \\ E-mail: SRMustafaeva@fa.ru) \\ (C) 2020 Петров Александр Михайлович \\ доктор экономических наук, профессор Департамента бизнес-аналитики \\ Финансовый университет при Правительстве РФ, Россия, Москва \\ E-mail: palmi@inbox.ru
}

Население страны является залогом ее процветания. Важно уделять пристальное внимание мониторингу и принятию определенных своевременных мер по улучшению демографической ситуации в стране. Основной целью исследования является оценка экономических затрат по оказанию медицинской помощи пожилому населению в Российской Федерации в контексте проблем старения населения. Важность анализа методологии оценки экономических затрат по оказанию медицинской помощи пожилому населению в Российской Федерации определяется требованиями времени, демографической обстановкой в целом.

Проблемы демографического старения негативным образом влияют на экономику любой страны, так как повышают расходы на социальное и медицинское обслуживание, увеличивают дефицит трудовых ресурсов, обеспечивают затруднения в части работы пенсионной системы той или иной страны.

Все проблемы, обозначенные выше, делают актуальным изучение особенностей процессов демографического старения и методологии оценки, экономических затрат по оказанию медицинской помощи пожилому населению в нашей стране.

Ключевые слова: анализ, демография, медицинская помощь, методология, оценка, пожилое население, экономика.

В экономической, социальной, политической, экологической средах постоянно проходят изменения. Одной из значимых проблем последнего времени является демографическое старение населения не только нашей страны, но и других стран мира. Демографическое старение - это длительный процесс, сопровождающийся различного рода изменениями. Для того, чтобы иметь более четкую картину о медикодемографической ситуации в Российской Федерации на сегодняшний день в рамках старения населения, необходимости оценки экономических затрат по оказанию медицинской помощи пожилому населению.
На фоне общего роста продолжительности жизни населения в Российской Федерации необходимо отметить не самую благоприятную тенденцию повышения доли пожилого населения к трудоспособному населению из-за снижения рождаемости и роста смертности в ряде регионов страны и, как следствие, увеличения среднего возраста населения в нашей стране. «Так, если в 2009 году этот показатель был на уровне 38,8 лет, то на начало 2019 года он составил 40,2 по стране в целом» [7].

Настораживает факт того, то «численность населения Российской Федерации в возрасте старше трудоспособного в 2018 году превысила 
37 млн. человек или $25 \%$ от общей численности населения» [6]. Показатели определяют продолжающиеся тенденции старения населения.

«Система здравоохранения пока еще не обеспечивает достаточность государственных гарантий медицинской помощи, ее доступность и высокое качество» [3], что обуславливает актуальность и значимость проведения всесторонних научных исследований в части анализа объемов, качества медицинской помощи, а также оценки экономических затрат по оказанию медицинской помощи пожилому населению.

Вопросы здоровья, продолжительности жизни населения нашей страны и ключевых показателей оказания медицинской помощи необходимо рассматривать системно и комплексно.

Российским государством в последние годы вливаются достаточно большие объемы инвестиций в здравоохранение. Однако, ситуация не улучшилась, поскольку не сопровождалась масштабными и высокоэффективными организационными и финансово-экономическими мероприятиями. Система здравоохранения Российской Федерации требует ключевых изменений в этой отрасли.

Ранее приказом Минздравсоцразвития Российской Федерации от 28.04.2011 № 364 [1] утверждена Концепция создания единой государственной информационной системы в сфере здравоохранения. Идея разработки подобной системы нацелена на улучшение ситуации по состоянию здоровья граждан и обеспечение качественного прорыва в системе здравоохранения Российской Федерации.

Оценка экономических затрат по оказанию медицинской помощи пожилому населению в Российской Федерации должна проводиться комплексно и отражать ряд задач (см. рисунок 1).

Не стоит забывать о затратах по информатизации системы здравоохранения. Развитие информатизации системы здравоохранения, включая внедрение эффективного электронного документооборота в медицинских организациях. Создание медицинского информационного и образовательного ресурса [4].

Решение указанных задач позволит улучшить здоровье и качество жизни населения нашей страны. Для улучшения обеспечения медицинской помощью предполагается обеспечить снижение уровня смертности от болезней системы кровообращения не менее чем в 1,4 раза, от несчастных случаев, отравлений и травм - примерно в 2 раза, снизить показатели младенческой и материнской смертности до показателей развитых стран, уменьшить в 1,5 раза заболеваемость социально значимыми заболеваниями.

Планируется примерно в 1,3 раза увеличить объем амбулаторной помощи, в первую очередь,

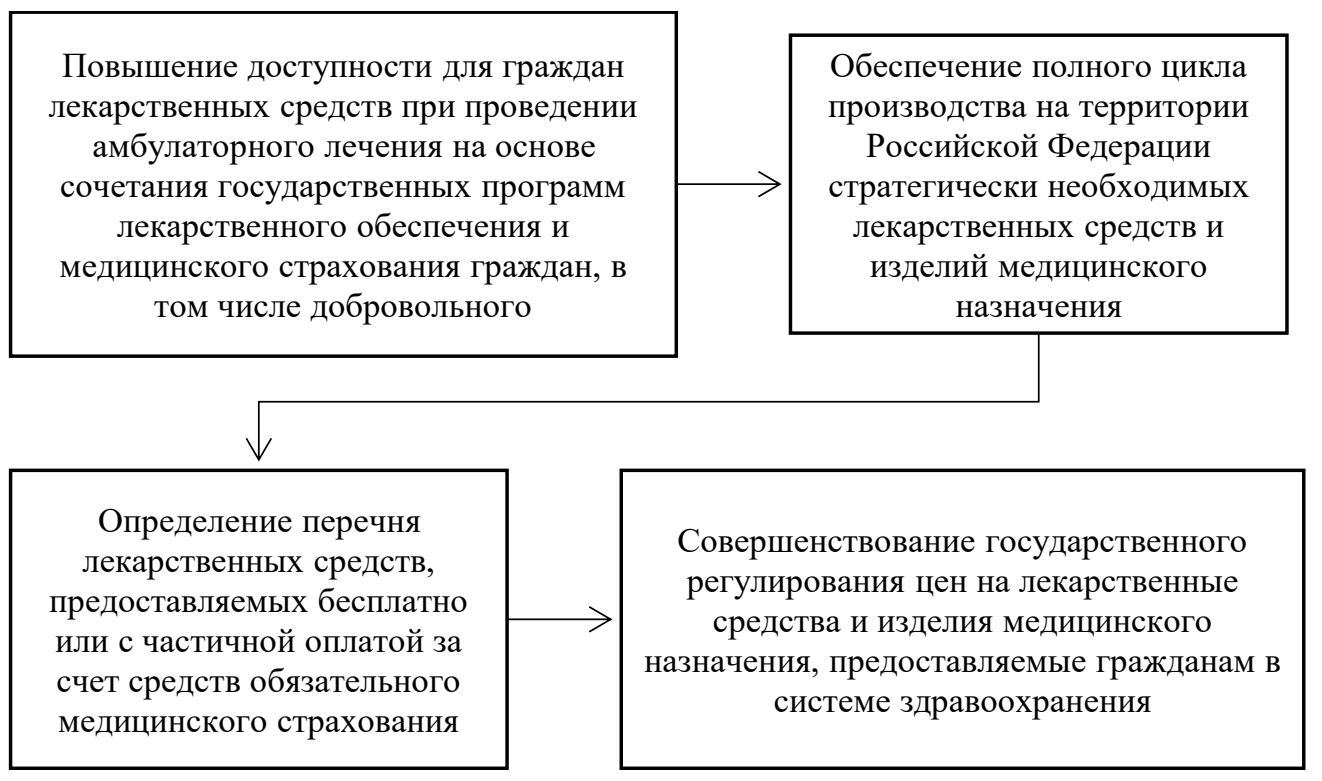

Рисунок 1. Комплексные задачи оценки экономических затрат [2] 
профилактической, позволяющей выявлять заболевания на ранних стадиях, значительно повысить эффективность использования коечного фонда (увеличить оборот и занятость койки, снизить среднюю длительность пребывания в стационаре и т.д.), обеспечить в полном объеме потребность населения нашей страны в высокотехнологичной медицинской помощи.

Улучшение показателей здоровья населения и деятельности организаций системы здравоохранения будет обеспечиваться на основе постоянной модернизации технологической базы отрасли, развития медицинской науки и образования, улучшения кадрового состава медицинских организаций.

Для достижения запланированных показателей предусматривается с 2008 по 2020 годы увеличить долю государственных расходов на систему здравоохранения в валовом внутреннем продукте с 3,6\% до не менее $5,2-5,5 \%$ (с учетом различий в паритете покупательной способности рубля и валют других стран доля государственных расходов на систему здравоохранения в валовом внутреннем продукте составит около $10-11 \%$, что сопоставимо с показателями передовых иностранных государств).

«Определение взаимосвязи между объемами медицинской помощи и состоянием здоровья пожилого населения построим на регрессионной зависимости между результативными признаками. За результативный признак примем темп роста численности пожилого населения, имеющего хронические заболевания, а также показатель, характеризующий объемы оказанной медицинской помощи населению, к которым отнесем следующие [8]:

$\mathrm{X} 1$ - Темп роста численности лиц пожилого возраста, обращавшихся за амбулаторнополиклинической помощью.

$\mathrm{X} 2$ - Темп роста численности лиц пожилого возраста, вызывавших скорую медицинскую помощь.

X3 - Темп роста численности лиц пожилого возраста, имевших случаи госпитализации в стационарной медицинской организации (МО). $\mathrm{X} 4$ - Темп роста числа МО стационарного типа.

X5 - Темп роста числа коек в МО стационарного типа.

Х6 - Темп роста численности врачей и среднего медицинского персонала.

X7 - Темп роста случаев позднего обращения в медицинские организации при наличии потребности в медицинской помощи».

«Если результативный признак реагирует на изменение ряда факторов, то данную зависимость можно представить в виде математической функции или уравнением регрессии» [5, 9]:

$\mathrm{Y}=0,101+0,035 \mathrm{X} 1+0,809 \mathrm{X} 2+0,869 \mathrm{X} 3$

$+0,042 \mathrm{X} 4+0,026 \mathrm{X} 5+0,124 \mathrm{X} 6-0,839 \mathrm{X} 7$

Полученное уравнение показывает, что увеличение количества лиц пожилого возраста, имеющих хронические заболевания, в значительной степени связано с ростом числа лиц пожилого возраста, имевших случаи госпитализации в стационар (увеличение данного фактора на $10 \%$ приведет к росту числа лиц пожилого возраста имеющих хронические заболевания на $8,69 \%)$.

Увеличение количества лиц пожилого возраста, имеющих хронические заболевания, напрямую связано и с другими показателями уравнения, за исключением случаев позднего обращения за медицинской помощью лиц пожилого возраста, имеющих хронические заболевания. Регрессионный анализ представляет рисунок 2.

Примененное в нашем исследовании уравнение подтверждает тот факт, что увеличение числа пожилых лиц, проходящих регулярное обследование, а также лечение в медицинских учреждениях приведет к увеличению количества лиц пожилого возраста, имеющих хронические заболевания, т.к. вырастает доля выявленных заболеваний, при этом снижается уровень смертности, что в свою очередь будет отражаться на объемах медицинской помощи. 


\begin{tabular}{|c|c|c|c|c|c|c|c|c|}
\hline ВЫВОД ИТОГОВ & & & & & & & & \\
\hline \multicolumn{9}{|c|}{ Регрессионная статистика } \\
\hline Множественный R & 0,994260062 & & & & & & & \\
\hline R-квадрат & 0,988553072 & & & & & & & \\
\hline Нормированный R-квадрат & 0,908424573 & & & & & & & \\
\hline Стандартная ошибка & 0,00946099 & & & & & & & \\
\hline Наблюдения & 9 & & & & & & & \\
\hline \multicolumn{9}{|l|}{ Дисперсионный анализ } \\
\hline & $d f$ & SS & MS & $F$ & Значимость F & & & \\
\hline Регрессия & 7 & 0,007730083 & 0,001104298 & 12,33709708 & 0,215890451 & & & \\
\hline Остаток & 1 & $8,95103 \mathrm{E}-05$ & $8,95103 \mathrm{E}-05$ & & & & & \\
\hline \multirow[t]{2}{*}{ Итого } & 8 & 0,007819593 & & & & & & \\
\hline & Коэффициенты & Стандартная ошибка & t-статистика & Р-Значение & Нижние 95\% & Верхние 95\% & Нижние 95,0\% & Bерхние 95,0\% \\
\hline Y-пересечение & 0,100961043 & 0,535901364 & 0,188394825 & 0,881453604 & $-6,708311404$ & 6,910233491 & $-6,708311404$ & 6,910233491 \\
\hline Переменная X1 & 0,03494698 & 0,262268384 & 0,133248922 & 0,915667873 & $-3,297488807$ & 3,367382766 & $-3,297488807$ & 3,367382766 \\
\hline Переменная X 2 & 0,8088365 & 0,125737326 & 6,432747726 & 0,098179609 & $-0,788807711$ & 2,406480711 & $-0,788807711$ & 2,406480711 \\
\hline Переменная X 3 & 0,869854264 & 0,379488241 & 2,292177118 & 0,26188921 & $-3,952001027$ & 5,691709555 & $-3,952001027$ & 5,691709555 \\
\hline Переменная X 4 & 0,041541283 & 0,180926683 & 2,296028555 & 0,261497714 & $-1,883478642$ & 2,714304301 & $-1,883478642$ & 2,714304301 \\
\hline Переменная X 5 & 0,026224122 & 0,374991961 & $-0,699324901$ & 0,611488311 & $-5,026965854$ & 4,502483421 & $-5,026965854$ & 4,502483421 \\
\hline Переменная X 6 & 0,123729669 & 0,068481706 & $-1,80675507$ & 0,321817588 & $-0,993872244$ & 0,746412906 & $-0,993872244$ & 0,746412906 \\
\hline Переменная X 7 & $-0,839038358$ & 0,253061248 & $-3,315554498$ & 0,186486296 & $-4,054486381$ & 2,376409665 & $-4,054486381$ & 2,376409665 \\
\hline
\end{tabular}

Рисунок 2. Регрессионный анализ (составлено авторами)

\section{Библиографический список}

1. Приказ Минздравсоцразвития России от 28.04.2011 № 364 (ред. от 12.04.2012) «Об утверждении Концепции создания единой государственной информационной системы в сфере здравоохранения».

2. Постановление Правительства РФ от 29.10.2010 № 865 (ред. от 03.04.2020) «О государственном регулировании цен на лекарственные препараты, включенные в перечень жизненно необходимых и важнейших лекарственных препаратов».

3. Распоряжение Правительства РФ от 17.11.2008 № 1662-р (ред. от 28.09.2018) «О Концепции долгосрочного социально-экономического развития Российской Федерации на период до 2020 года» (вместе с «Концепцией долгосрочного социально-экономического развития Российской Федерации на период до 2020 года»).

4. Распоряжение Правительства РФ от 28.12.2012 № 2580-р «Об утверждении Стратегии развития медицинской науки в Российской Федерации на период до 2025 года».

5. Музалева Т.И. Статистическое измерение и оценка результатов деятельности органов внутренних дел Российской Федерации: диссертация ... кандидата экономических наук: 08.00.12 - Москва. 2012, 236 с.

6. Институт демографии Национального исследовательского университета «Высшая школа экономики» http://www.demoscope.ru/weekly/2019/0797/barom01.php.

7. Нацпроекты. Назван средний возраст россиян https://lenta.ru/news/2019/09/12/age.

8. https://www.mpsu.ru/upload/iblock/ab0/ab05db8a3b291cadbad186dca2e14fc6.pdf\#2.

9. http://emll.ru/find?iddb=17\&ID=RUCML-BIBL-0001346533. 